Research Paper

\title{
Temporomandibular Disorders and Oral Features in Early Rheumatoid Arthritis Patients: An Observational Study
}

\author{
Vito Crincoli1 ${ }^{\bowtie}$, Maria Grazia Anelli², Eleonora Quercia ${ }^{3}$, Maria Grazia Piancino4, Mariasevera Di Comite $^{1}$
}

1. Department of Basic Medical Sciences, Neurosciences and Sensory Organs, “Aldo Moro" University of Bari, Italy.

2. Complex Operating Unit of Rheumatology, A.O.U. Policlinico of Bari, Italy.

3. Graduated Student, "Aldo Moro" University of Bari, Italy.

4. Department of Surgical Sciences, University of Turin, Italy.

$\triangle$ Corresponding author: Prof. Vito Crincoli, Department of Basic Medical Sciences, Neurosciences and Sensory Organs, Piazza Giulio Cesare 11, 70124, Bari, Italy. Phone: 00390805478051; Fax: 00390805478743; e-mail: vito.crincoli@uniba.it

(C) Ivyspring International Publisher. This is an open access article distributed under the terms of the Creative Commons Attribution (CC BY-NC) license (https://creativecommons.org/licenses/by-nc/4.0/). See http://ivyspring.com/terms for full terms and conditions.

Received: 2018.07.07; Accepted: 2018.11.29; Published: 2019.01.01

\begin{abstract}
Aims: Temporomandibular disorders (TMD) represent a heterogeneous group of inflammatory or degenerative diseases of the stomatognatic system, with algic and/or dysfunctional clinical features involving temporomandibular joint (TMJ) and related masticatory muscles. Rheumatoid Arthritis (RA) is an autoimmune polyarthritis characterized by the chronic inflammation of synovial joints and oral implications such as hyposalivation, difficulty in swallowing and phoning, feeling of burning mouth, increased thirst, loss of taste or unpleasant taste and smell, dental sensitivity.

The aim of this observational study was to investigate the prevalence of TMD symptoms and signs as well as oral implications in patients with Early Rheumatoid Arthritis (ERA), that is a RA diagnosed within 12 months, compared with a control group.

Methods: The study group included 52 ERA patients ( 11 men, 41 women) diagnosed according to the 2010 ACR/EULAR Classification Criteria for Rheumatoid Arthritis. A randomly selected group of 52 patients not affected by this disease, matched by sex and age, served as the control group. The examination for TMD signs and symptoms was based on the standardized Research Diagnostic Criteria for Temporomandibular Disorders (RDC/TMD) by means of a questionnaire and through clinical examination.

Results: Regarding the oral kinematics, the left lateral excursion of the mandible was restricted in statistically significant way in ERA patients $(p=0.017)$. The endfeel values were significantly increased in ERA group $(p=0.0017)$, thus showing the presence of a higher muscle contracture. On the other side, the study group complained less frequently (67.3\%) of TDM symptoms (muscle pain on chewing, pain in the neck and shoulders muscles, difficulty in mouth opening, arthralgia of TMJ, tinnitus) than controls $(90.4 \%)\left(X^{2}=8.301 p=0.0039\right)$. The presence of TMJ noises was significantly lower in the study group $\left(X^{2}=3.869 p=0.0049\right)$, as well as presence of opening derangement $\left(X^{2}=14.014 p=0.0002\right)$.

The salivary flow was significantly decreased in the study group respect to the control one $(p<0.0001)$.

Conclusions: The data collected show a weak TMJ kinematic impairment, a paucisymptomatic muscle contracture (positive endfeel) and a remarkable reduction of salivary flow in ERA patients. Myofacial pain (MP) evoked by palpation was more frequent and severe in the control group than in the study one, this result being highly significant.
\end{abstract}

Key words: Early Rheumatoid Arthritis, temporomandibular disorders, RDC/TMD, oral implications.

\section{Introduction}

Rheumatoid arthritis (RA) is a systemic inflammatory polyarthritis, characterized by a predisposition for affecting and destroying the small joints of the hands and feet (although any synovial joint can be virtually affected) [1]. It also can involve several extra-articular organs. 
The prevalence of RA is approximately $1 \%$ worldwide [2]. In industrialized countries, it affects $0,5-2 \%$ of population, with an incidence of $12-200$ cases every 100.000 [3]. The incidence of new cases increases with age: the illness begins more commonly between 40 and 50 years (a little later in men) [4], but it can anyhow appear at any age. Regarding sex, RA affects women more frequently than men, in a ratio of 2-4:1 [2]. Individuals affected have a high risk of incurring in disability and premature death, and they develop a probability of exitus twice higher than healthy individuals of the same age.

RA is a chronic, stiffing and progressive disease, of unknown etiology, in which both genetic and environmental factors participate in mechanisms of pathogenesis [5]. The heritability of RA is estimated to be approximately $65 \%$ [6]. Genetic factors increase susceptibility to RA, such as the frequency of the serotypes of HLA-DR4, one of HLA class II genes [7]. Other serotypes, such as DR1, are also associated with an increased risk for RA, although to a lesser extent than DR4 [8]. However, also non-MHC genes are also associated with RA [9]. At 2014, 101 RA risk loci have been identified [10], including PADI4, PTPN22, TNFAIP3, TRAF1 / C5, REL, CCR6, FCRL3 OLIG3/TNFAIP3, STAT4, TRAF1-C5, many of them involved in immune cell functions [8]. In addition to genetic factors, several environmental ones have been involved in the pathogenesis of RA, such as virus (Epstein-Barr, parvovirus B19), bacteria (Streptococcus, Mycoplasma, Proteus and E. coli), hormones, cigar and silica [11, 12].

Therefore, a high-risk genetic background, in combination with epigenetic marks and environmental exposures, leads to a cascade of events inducing synovitis [13], characterized by hyperplasia of the synovial lining (normally formed by two or three layers of synovial fibroblasts), that reaches a thickness of 10-15 cell layers (rheumatoid pannus), and invades and degrades the cartilage matrix and the subchondral bone, promoting joint destruction [14]. The anti-CCP antibodies (ACPAs), in addition to the proinflammatory cytokines, cause the local bone resorption [15]. Indeed, sera from the majority of RA patients contain autoantibodies like rheumatoid factor (RF) or anti-citrullinated protein antibodies (ACPAs). However, approximately $20 \%$ of RA are seronegative [8], so the values of ANA (antinuclear antibodies), CRP (C-reactive protein), ESR (erythrocyte sedimentation rate), $\mathrm{Hb}$ (hemoglobin), PLT (platelets) and WBC (white blood cells) must also be sought. The clinical diagnosis, far more important than the serological one, carries out through musculoskeletal objectivities and extraarticular manifestations. Furthermore, radiographs and several clinical imaging systems, such as magnetic resonance imaging (MRI), computed tomography (CT), ultrasonography (US), dual-energy X-ray absorptiometry (DXA) and digital X-ray radiogrammetry (DXR), are used to monitor bone changes in RA [16].

The diagnosis performed through the ERA criteria within 12 months after the onset of clinical symptoms, is considered early [17].

RA mainly affects the joints of the hands, wrists, elbows, shoulders, hips, knees, feet; less frequently, it involves other joints, such as the temporomandibular ones. From 4 up to $80 \%$ of RA patients (usually, more than $50 \%$ of them) clinically exhibit TMJ involvement [18]. The clinical findings in the TMJ affected by RA are pain, swelling, movement impairment and crepitation; moreover, in advanced stages, malocclusion of the teeth and anterior open bite may occur [19]. There is sensitivity or preauricular pain during joint movement, probably due to compression of retrodiscal tissue, stretching of the joint capsule and synovitis. There is also morning stiffness usually lasting more than $30 \mathrm{~min}$ and decreased masticatory force. In children, it may result in disturbance in mandibular growth, facial deformity and ankylosis, generally found in the later stages of the disease, but it is a rare finding [18]. The presence of morphologic alterations on conventional radiographs of the TMJ in RA patients varies from $19 \%$ to $86 \%$ [20]. The main changes are flattening, spiked deformity or pencil-like condylar head, cortical erosion, gradual decrease in joint space due to granulation, deossification, and sub cortical cysts [21, 22]. The use of the drugs can be associated with adverse events in the oral cavity, such as changes in mucous membranes and other symptoms different from patient to patient [23]. About half of the patients with RA (51.5\%) complain xerostomia and, consequently, difficulties in swallowing and phonation, sensation of burning mouth, increased thirst, loss of taste, unpleasant taste and odor and dental sensitivity [24].

Nevertheless, the literature lacks studies about TMJ and masticatory muscles involvement in patients with ERA, so the relationship between this disease and the temporomandibular disorders is unclear [25]. Given this background, the aim of this study was to evaluate clinically, through signs and symptoms, the prevalence of temporomandibular disorders (TMD) and oral manifestations in a sample, homogeneous for ethnic origin, of ERA patients on drug therapy compared with a control group. If a significant correlation could be found, the complex relationship between this autoimmune disease and orofacial manifestations could be better understood. 
The null hypothesis in this research was that ERA patients presented no differences in clinical characteristics and functional disabilities compared to a control group.

\section{Materials and Methods}

This clinical observational study was performed between June 2016 and February 2018 at the School of Dentistry and the Complex Operating Unit of Rheumatology, University of Bari, Italy, in accordance with the provisions of the Declaration of Helsinki. Ethical approval and informed consent from each human subject were obtained.

Fifty-two patients (11 men, 41 women) of European origins with ERA, diagnosed according to ERA Criteria, were enrolled in the study group. A control group (CG) of 52 patients, matched by sex and age, was randomly selected among those presenting at the Dental Clinic for routine oral visit. The CG did not have any history of rheumatic disease.

Exclusion criteria were previous facial trauma, head, oral or neck neoplasia, maxillofacial surgery.

Patients age ranged between 8 and 86 years old, with a mean age of $55,96(\mathrm{SD}=19,01)$ years in the ERA group, and 52,73 (SD=15,82) years in the controls. Patients' drugs were recorded. The absolute level of disease activity was quantified through three indices: Disease activity score 28 (DAS28), Clinical Disease Activity Index (CDAI), and Simplified Disease Activity Index (SDAI).

The TMD were assessed following the standardized Research Diagnostic Criteria for Temporomandibular Disorders (RDC/TMD) [26]. A single, skilled, nonblinded practitioner valued current symptoms and signs of both groups through an anamnestic questionnaire and clinical examination.

\section{Patient's History}

\section{Oral symptoms}

Through a questionnaire, patients recorded the presence/absence of the following diseases:

a) Xerostomia: it is a complaint of dryness of oral cavity, due to a hyposalivation or to a complete lack of saliva [27]. It is classified as true xerostomia (xerostomia primaria), resulting from malfunction of the salivary glands, or pseudo xerostomia (xerostomia symptomatica), in the course of which the patient has a subjective impression of oral dryness despite a normal secretory function. Xerostomia affects mostly menopausal women and individuals above 65 years of age [28]. It is associated to discomfort in activities such as eating, speaking, swallowing and wearing dentures.

b) Dysgeusia: it is an inability to discriminate all the basic tastes (total dysgeusia), often due to a zinc deficiency, or a limited number of basic tastes (partial dysgeusia) [29], due to an obstruction of selective taste receptors in taste cells, that can be induced by an autoimmune mechanism [30]. Dysgeusia was recorded when subjects experienced bitter, sour, or metallic flavors [31].

c) Stomatodynia: it is a condition often with an unclear etiopathogenesis, in which affected individuals complain of burning pain of the oral mucosa, especially on the tongue, accompanied by other sensory disorders such as xerostomia and dysgeusia [32].

\section{TMD symptoms}

All complaints reported by patients were recorded through a questionnaire: (i) presence of pain in masticatory muscles (both at rest and during mandibular functions), (ii) pain or stiffening in the neck and shoulders muscles, (iii) difficulty in mouth opening, (iv) arthralgia of TMJ, (v) temporal headaches and tinnitus [33, 34, 35].

These data were collected as categorical ones (presence/absence of TMD).

\section{Clinical Examination}

\section{Disease Activity}

To quantify the absolute level of disease activity of ERA patients, the mean values of three indices were used: (i) Clinical Disease Activity Index = CDAI), (ii) Simplified Disease Activity Index (SDAI) and (iii) Disease activity score in 28 joints (DAS28).

\section{Pharmacological Therapy}

ERA patients were asked about RA medication and about the beginning of treatment after diagnosis.

\section{Oral signs}

The following data were collected as categorical (presence/absence) of:

- ulcers (aphthae)

- erythema

- candidiasis

- angular cheilitis: is characterized by erythema, ulcerations, flaking of the labial and sting. The buccal opening is limited and painful.

- hyperkeratotic or erythematous areas of the mucosa.

- fissured tongue: presence of deep grooves on the tongue surface.

- petechiae: small $(<3 \mathrm{~mm})$ red or purple spots, caused by a minor bleed from broken blood vessels. 
Hyposalivation: is a result of several conditions, including dehydration, denervation, trauma, chronic immune and non-immune mediated inflammation of the salivary glands, head and neck irradiation therapy, psychologic factors and medications such as anticoagulants, antidepressants, antihypertensives, antiretrovirals, hypoglycemics, levothyroxine, multivitamins and supplements, non-steroidal anti-inflammatory drugs and steroid inhalers [36]. Hyposalivation is considered to appear when the unstimulated salivary flow (UWS) rate is < $0.1 \mathrm{~mL} / \mathrm{min}$ or the stimulated one (SWS) is < $0.7 \mathrm{~mL} / \mathrm{min}$. [37].

In this study the test was conducted asking the patient to spit saliva, accumulated in the floor of the mouth without stimulation, in a graduated tube every 60 seconds. The collection period lasted 5 minutes.

Other oral characteristics analyzed were the integrity of the dental arches or presence of partial or total edentulism, the presence/absence of prostheses (mobile, fixed or both), and any previous or present orthodontic treatment.

\section{TMJ signs}

a) TMJ sounds (TMJs): they are perceived by placing the fingertips on the lateral surface of the condyle on each side separately, during the opening and closing movements of the mandible.

Clicking is considered a net, sharp and short-lived noise. It can be single or reciprocal, early or late.

Snapping sound is a "short duration" clicking, louder, sharper and with a higher pitch [38]. It's also known as "pop noise". Crepitation is a gravel-like noise, composed of a series of short duration sounds, occurring in rapid succession, [39], with a low pitch, also described as the gears of a cogwheel.

b) Bruxism (BRUX): is defined by the American Academy of Sleep Medicine as the "repetitive jaw muscle activity, characterized by the clenching or grinding of teeth" [40]. There are two forms of bruxism: sleep bruxism (SB) or awake bruxism (AB), which are considered separate entities that differ in their etiology [41]. While AB is characterized mainly by the clenching of teeth [42], SB by the clenching and grinding [40]. Bruxism can cause myalgia (due to ischemia and an accumulation of metabolic biomarkers in the muscle tissue) [43], joint pain and oral signs, such as wear facets that alter the occlusal plane, irregular lingual edges and buccal occlusal line.

c) Mandibular kinematics (MK) and restriction of movements (RM):

i) Reduced opening: in a healthy masticatory system, the mouth opens between 53 and $58 \mathrm{~mm}$. Taking into account overbite [44], an opening movement is considered restricted when the distance between the incisal edge of the maxillary and mandibular incisors is lower than $40 \mathrm{~mm}$.

ii) Right and left lateral shifts: were recorded when the distance from upper to lower midline was < $8 \mathrm{~mm}$.

iii) Mandibular protrusion: the mean values range between 7 and $10 \mathrm{~mm}$. It was recorded when < $7 \mathrm{~mm}[45]$.

iv) Endfeel: this parameter assesses the extent of muscle contracture. It was tested by placing the thumb and the index fingers between patient's upper and lower teeth and applying a firm force to passively increase the incisal distance. It was recorded as "positive" when greater than $2 \mathrm{~mm}$, due to the physiological stretching of the ligaments (joint play).

d) Opening derangement (OD): in a healthy masticatory system, the movement of the jaw in the opening path is straight. The alterations in the course of opening have been classified as:

i) deviation: any shift of the jaw from the midline during opening that disappears continuing the opening (return of the jaw to the midline);

ii) deflection: any shift of the mandibular midline that increases continuing opening and does not disappear in maximum opening (jaw doesn't return to the midline) [46].

\section{Myofacial pain (MP)}

While healthy muscles do not elicit pain when palpated, ache may be elicited by compression of inflamed or contracted muscles. These data were collected as categorical (presence/absence of pain) through digital palpation of the masticatory muscles, performed mainly by the thumb and the index finger, applying a soft but firm pressure to the muscle.

The following masticatory muscles were palpated bilaterally: anterior, medial, and posterior temporalis muscle, superficial and deep masseter muscle, medial pterygoid muscle, lateral pterygoid muscle with its superior and inferior head, digastric (anterior and posterior belly) muscle, mylohyoid and sternocleidomastoid muscles.

Patients were also asked to express the intensity of perceived pain for each muscle, using the VAS scale (from 0 to 3) [47].

\section{Statistical Analysis}

Categorical data were expressed as number and percentage and comparisons between ERA and control patients were performed using chi-squared $\left(x^{2}\right)$ test and, if not applicable, Fisher or Mid-p exact tests. Quantitative data were presented as mean and Standard Deviation (SD) and the comparisons between two groups were valued by means of 
Student's $\mathrm{T}$ test for unpaired samples. In all comparisons, a $p$ value $\leq 0.05$ was considered statistically significant. Statistical analyses were performed by using Epi Info 3.5 for categorical data and GraphPad Prism 6.0 for quantitative ones.

\section{Results}

\section{Characteristic of ERA Patients and Controls}

Patients' age ranged between 8 and 86 years, $78.8 \%$ were female and $21.2 \%$ were male in both groups. The two groups, matched for age and sex, resulted quite similar for sociodemographic aspects. However, retirees were prominent in the study group, while housewives were more numerous in the control one (Table 1).

Table 1. Sociodemographic characteristics of ERA patients and controls.

\begin{tabular}{lllll}
\hline $\begin{array}{l}\text { Sociodemographic } \\
\text { Characteristics }\end{array}$ & ERA & Controls & Test & p Value \\
\hline $\begin{array}{l}\text { Age, mean } \pm \text { SD } \\
\text { Sex, } \mathrm{n}(\%)\end{array}$ & $55,96 \pm 19,01$ & $52,73 \pm 15,82$ & & \\
male & $11(21,2 \%)$ & $11(21,2 \%)$ & & \\
female & $41(78,8 \%)$ & $41(78,8 \%)$ & & \\
Educational degree, $\mathrm{n}(\%)$ & & & \\
primary & $12(24,5 \%)$ & $12(24,0 \%)$ & $\chi^{2}=1,731$ & 0,630 \\
secondary & $13(26,5 \%)$ & $9(18,0 \%)$ & & \\
high & $16(32,7 \%)$ & $22(44,0 \%)$ & & \\
academic & $8(16,3 \%)$ & $7(14,0 \%)$ & & \\
Occupation, n (\%) & & & & \\
housewife & $10(19,2 \%)$ & $20(38,5 \%)$ & $\chi^{2}=26,746$ & 0002 \\
office worker & $10(19,2 \%)$ & $2(3,8 \%)$ & & \\
retired & $14(26,9 \%)$ & $5(9,6 \%)$ & & \\
self employed & $10(19,2 \%)$ & $3(5,8 \%)$ & & \\
public employed & $4(7,7 \%)$ & $19(36,5 \%)$ & & \\
not employed & $4(7,7 \%)$ & $3(5,8 \%)$ & & \\
Marital status, $\mathrm{n}(\%)$ & & & & \\
married & $33(63,5 \%)$ & $34(65,4 \%)$ & $\chi^{2}=3,348$ & \\
widower & $4(7,7 \%)$ & $8(15,4 \%)$ & & \\
single & $11(21,2 \%)$ & $9(17,3 \%)$ & & \\
divorced & $4(7,7 \%)$ & $1(1,9 \%)$ & & \\
\hline
\end{tabular}

Comorbidities of ERA patients and controls are reported in Table 2.

Table 2. Clinical characteristics of ERA patients and controls.

\begin{tabular}{|c|c|c|c|c|}
\hline Comorbidities & ERA & Controls & Test & p Value \\
\hline Cardiopathy & $7(13,5 \%)$ & $5(9,6 \%)$ & $X^{2}=0,377$ & 0,539 \\
\hline Diabetes mellitus & $4(7,7 \%)$ & $3(5,8 \%)$ & $\begin{array}{l}\text { Fisher's exact } \\
\text { test }\end{array}$ & 0,500 \\
\hline Hypertension & $26(50,0 \%)$ & $13(25 \%)$ & $X^{2}=6,933$ & $0,008^{*}$ \\
\hline Hypovitaminosis D & $38(73,1 \%)$ & $1(1,9 \%)$ & $X^{2}=56,164$ & $<0,001^{*}$ \\
\hline Osteoporosis & $17(32,7 \%)$ & $1(1,9 \%)$ & $X^{2}=17,199$ & $<0,001^{*}$ \\
\hline Esophageal disease & $11(21,2 \%)$ & $0(0,0 \%)$ & $X^{2}=12,301$ & $<0,001^{*}$ \\
\hline Gastroenteric disease & $6(11,5 \%)$ & $1(1,9 \%)$ & $\begin{array}{l}\text { Fisher's exact } \\
\text { test }\end{array}$ & 0,056 \\
\hline Lung disease & $8(15,4 \%)$ & $0(0,0 \%)$ & $\begin{array}{l}\text { Fisher's exact } \\
\text { test }\end{array}$ & $0,003^{*}$ \\
\hline Kidney disease & $7(13,5 \%)$ & $1(1,9 \%)$ & $\begin{array}{l}\text { Fisher's exact } \\
\text { test }\end{array}$ & $0,029^{*}$ \\
\hline Thyroid disease & $19(36,5 \%)$ & $7(13,5 \%)$ & $X^{2}=7,385$ & $0,006^{*}$ \\
\hline Neurological disease & $2(3,8 \%)$ & $1(1,9 \%)$ & $\begin{array}{l}\text { Fisher's exact } \\
\text { test }\end{array}$ & 0,500 \\
\hline Raynaud disease & $0(0,00 \%)$ & $0(0,0 \%)$ & - & - \\
\hline
\end{tabular}

\section{Disease Activity}

The CDAI score indicates on average a low disease activity (from $>2.8$ to 10.0); also the score of SDAI indicates a low disease activity (from $>3.3$ to $\leq 11.0)$. DAS 28 indicates that on average the disease is in clinical remission $(<2.6)$ (Table 3$)$.

Table 3. Activity indexes of ERA.

\begin{tabular}{ll}
\hline Activity indexes of ERA & Mean \pm SD \\
\hline CDAI (range $0-76,0$ ) & $2,953 \pm 5,892$ \\
SDAI (range 0- 86,0) & $3,572 \pm 6,028$ \\
DAS28 (range $0-9,4$ ) & $2,469 \pm 1,764$ \\
\hline
\end{tabular}

\section{Pharmacological Therapy}

Approximately $42 \%$ of patients with ERA take corticosteroid medications, almost 80\% sDMARDs (synthetic disease-modifying antirheumatic drugs), and about $34 \%$ biologic DMARDs (bDMARDs). Many of them take combined therapies (Table 4).

Table 4. Pharmacological therapy in ERA patients.

\begin{tabular}{ll}
\hline Pharmacological therapy & Patients \\
\hline Corticosteroids & $22(42,3 \%)$ \\
SDMARDs & $41(78,8 \%)$ \\
bDMARDs & $18(34,6 \%)$ \\
\hline
\end{tabular}

Regarding the beginning of treatment, $90.4 \%$ of patients started drug therapy within 4 months after diagnosis of ERA, 3.8\% between 4 and 8 months after diagnosis, $5.8 \%$ after 8 months.

\section{Oral Characteristics}

The oral characteristics analyzed were the presence/absence of partial or total edentulism, the presence/absence of prostheses (mobile, fixed or both), and any previous or present orthodontic treatment. Among the three parameters, only the presence of prostheses was significantly prominent in ERA patients $(50.0 \%)$. These data were analyzed using the $\chi^{2}$ test (Table 5).

Table 5. Oral characteristics of ERA patients and controls.

\begin{tabular}{lllll}
\hline Oral characteristics & ERA & Controls & Test & p Value \\
\hline Partial or total edentulism & $28(53,8 \%)$ & $21(40,4 \%)$ & $\mathrm{X}^{2}=1,891$ & 0,169 \\
$\begin{array}{l}\text { Presence of prostheses (mobile, } \\
\text { fixed, partial or total) }\end{array}$ & $26(50,0 \%)$ & $10(19,2 \%)$ & $\mathrm{X}^{2}=10,875$ & $<0,001^{*}$ \\
$\begin{array}{l}\text { Present or previous orthodontic } \\
\text { treatments }\end{array}$ & $8(15,4 \%)$ & $6(11,5 \%)$ & $\mathrm{X}^{2}=0,330$ & 0,565 \\
\hline
\end{tabular}

\section{Oral Symptoms}

Statistically significant differences were not found in the study group and in the control one $(p>0,05)$. Presence of xerostomia, dysgeusia and stomatodynia results qualitatively overlapping in the two groups. These data were analyzed using the $x^{2}$ test and the Fisher exact test (Table 6). 
Table 6. Oral symptoms of ERA patients and controls.

\begin{tabular}{lllll}
\hline Oral symptoms & ERA & Controls & Test & p Value \\
\hline Xerostomia & $14(26,9 \%)$ & $9(17,3 \%)$ & $X^{2}=1,396$ & 0,237 \\
Dysgeusia & $1(1,9 \%)$ & $3(5,8 \%)$ & Fisher's exact test & 0,308 \\
Stomadodynia & $1(1,9 \%)$ & $2(3,8 \%)$ & Fisher's exact test & 0,500 \\
\hline
\end{tabular}

\section{TMD}

\subsection{Symptoms}

The valuation of TMDs showed that $67,3 \%$ of the patients with ERA and $90,4 \%$ of the controls complained one or more symptoms. Statistically significant differences were found for all subjective complaints, except for masticatory muscle pain $(p=0,237)$ and for temporal headache $(p=0,315)$. These data were analyzed using the $\chi^{2}$ test (Table 7).

Table 7. TMD symptoms in ERA patients and controls.

\begin{tabular}{|c|c|c|c|c|}
\hline TMD symptoms & ERA & Controls & $\begin{array}{l}\mathrm{X}^{2} \\
\text { Test }\end{array}$ & $\begin{array}{l}\mathrm{p} \\
\text { Value }\end{array}$ \\
\hline Masticatory muscle pain & $9(17,3 \%)$ & $14(26,9 \%)$ & 1,395 & 0,237 \\
\hline $\begin{array}{l}\text { Soreness or muscle pain of neck and } \\
\text { shoulders }\end{array}$ & $22(42,3 \%)$ & $37(71,2 \%)$ & 8,814 & $0,002^{*}$ \\
\hline Muscle pain during the function & $11(21,2 \%)$ & $25(48,1 \%)$ & 8,326 & $0,003^{*}$ \\
\hline Arthralgia tmj & $13(25,0 \%)$ & $28(53,8 \%)$ & 9,059 & $0,002^{*}$ \\
\hline Difficulty opening mouth & $6(11,5 \%)$ & $23(44,2 \%)$ & 13,818 & $<0,001^{*}$ \\
\hline Temporal headache & $18(34,6 \%)$ & $23(44,2 \%)$ & 1,006 & 0,315 \\
\hline Tinnitus & $13(25,0 \%)$ & $29(55,8 \%)$ & 10,224 & $0,001^{*}$ \\
\hline TOTAL & $35(67,3 \%)$ & $47(90,4 \%)$ & 8,301 & $0,004^{*}$ \\
\hline
\end{tabular}

\subsection{Myofacial pain}

For almost all muscles examined through palpation, pain reported was significantly higher in the control group than in the study one $(p \leq 0,05)$. No significant differences between the two groups were found for medial temporal muscles, sternocleidomastoid muscles (clavicular head) and for superficial and deep masseter muscles. These data were analyzed using the $\chi^{2}$ test (Table 8 ).

Table 8. Myofascial pain in ERA patients and controls.

\begin{tabular}{lccll}
\hline Pain on muscle palpation & ERA & Controls & X $^{2}$ Test & p Value \\
\hline Anterior temporalis muscle & $7(13,5 \%)$ & $27(51,9 \%)$ & 17,479 & $<0,001^{*}$ \\
Medial temporalis muscle & $5(9,6 \%)$ & $7(13,5 \%)$ & 0,376 & 0,539 \\
Posterior temporalis muscle & $4(7,7 \%)$ & $14(26,9 \%)$ & 6,718 & $0,009^{*}$ \\
$\begin{array}{l}\text { Sternocleidomastoid } \\
\text { muscles - sternal head }\end{array}$ & $11(21,2 \%)$ & $24(46,2 \%)$ & 7,277 & $0,006^{*}$ \\
$\begin{array}{l}\text { Sternocleidomastoid } \\
\text { muscles - clavicular head }\end{array}$ & $11(21,2 \%)$ & $15(28,8 \%)$ & 0,820 & 0,365 \\
$\begin{array}{l}\text { Digastric muscle-anterior belly } \\
\text { Digastric muscle-posterior belly }\end{array}$ & $2(3,8 \%)$ & $14(26,9 \%)$ & 10,636 & $0,001^{*}$ \\
Superficial masseter muscles & $22(42,3 \%)$ & $18(34,6 \%)$ & 9,434 & $0,002^{*}$ \\
$\begin{array}{l}\text { Deep masseter muscles } \\
\text { Medial pterygoid muscles }\end{array}$ & $22(42,3 \%)$ & $25(48,1 \%)$ & 0,349 & 0,554 \\
Lateral pterygoid muscles & $11(21,2 \%)$ & $30(57,7 \%)$ & 14,535 & $<0,001^{*}$ \\
Mylohyoid muscles & $27(51,9 \%)$ & $39(75,0 \%)$ & 5,971 & $0,014^{*}$ \\
TOTAL & $6(11,5 \%)$ & $25(48,1 \%)$ & 16,59 & $<0,001^{*}$ \\
\hline
\end{tabular}

\section{TMJ Signs}

5.1. TMJ sounds: overall, there was a light reduction in joint noises in the group of ERA patients compared to the control one, but no statistically significant difference was detected. These data were analyzed using the $\chi^{2}$ test (Table 9).

Table 9. TMJ noises in ERA patients and controls.

\begin{tabular}{lccll}
\hline TMJ noises & ERA & Controls & $\mathbf{X}^{2}$ Test & p Value \\
\hline $\begin{array}{l}\text { Clicking during the } \\
\text { opening }\end{array}$ & $7(13,5 \%)$ & $12(23,1 \%)$ & 1,609 & 0,204 \\
$\begin{array}{l}\text { Reciprocal clicking } \\
\text { Snapping }\end{array}$ & $6(11,5 \%)$ & $8(15,4 \%)$ & 0,330 & 0,565 \\
Crepitation & $9(17,3 \%)$ & $14(26,9 \%)$ & 1,396 & 0,237 \\
TOTAL & $12(23,1 \%)$ & $8(15,4 \%)$ & 0,990 & 0,319 \\
\hline
\end{tabular}

5.2 Bruxism: the prevalence of clenching showed a statistically significant decrease in ERA patients compared with controls. In detail, dental wear facets were more present in the control group in a statistically significant way, while irregular lingual edges and buccal occlusal line showed no significant differences among the two groups. These data were analyzed using the $\chi^{2}$ test (Table 10).

Table 10. Bruxism and its oral signs in ERA patients and controls.

\begin{tabular}{lllll}
\hline $\begin{array}{l}\text { Bruxism and oral } \\
\text { signs }\end{array}$ & ERA & Controls & $\mathbf{X}^{2}$ Test & p Value \\
\hline $\begin{array}{l}\text { Teeth clenching } \\
\begin{array}{l}\text { Bruxism (Teeth } \\
\text { grinding) }\end{array}\end{array}$ & $9(17,3 \%)$ & $27(51,9 \%)$ & 13,765 & $<0,001^{*}$ \\
$\begin{array}{l}\text { Wear facets } \\
\text { Irregular lingual edges }\end{array}$ & $16(30,8 \%)$ & $15(28,8 \%)$ & 1,950 & 0,163 \\
Buccal occlusal line & $13(25,0 \%)$ & $12(23,0 \%)$ & 0,052 & $0,006^{*}$ \\
\hline
\end{tabular}

\subsection{Mandibular kinematics (MK) and restriction}

of movements (RM): values of active mouth opening, right lateral excursion and protrusion (calculated by T-student test) showed no statistically significant difference between ERA and control patients. Left lateral excursion, on the contrary, resulted restricted in statistically significant way in ERA patients $(p=0,017)$ (Fig. 1). Finally, the end-feel, considered positive for values $>2 \mathrm{~mm}$, was increased in both groups, but more significantly in the group of sick subjects (Fig. 2). This finding shows objectively the presence of a muscle contracture in patients with ERA $(p=0,002)$ (Table 11).

Table 11. Mean values of mandibular kinematics in ERA patients and controls.

\begin{tabular}{llll}
\hline $\begin{array}{l}\text { Mean values of mandibular } \\
\text { kinematics (Mean in } \mathbf{m m} \pm \text { SD) }\end{array}$ & ERA & Controls & p Value \\
\hline $\begin{array}{llll}\text { Maximal active mouth opening } \pm \\
\text { SD }\end{array}$ & $42,78 \pm 6,03$ & $42,83 \pm 5,60$ & 0,970 \\
Right lateral excursion \pm SD & $6,37 \pm 2,98$ & $7,37 \pm 2,43$ & 0,07 \\
Left lateral excursion \pm SD & $6,35 \pm 3,29$ & $7,79 \pm 2,56$ & $0,017^{*}$ \\
Protrusion \pm SD & $4,33 \pm 3,25$ & $5,39 \pm 2,58$ & 0,076 \\
Endfeel \pm SD & $3,95 \pm 1,28$ & $2,96 \pm 1,10$ & $0,002^{*}$ \\
\hline
\end{tabular}


A

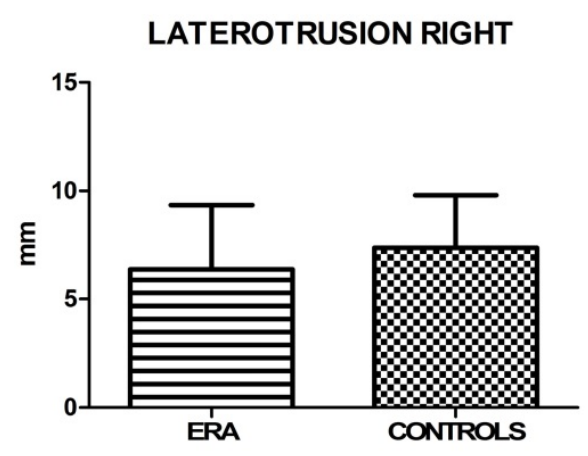

B

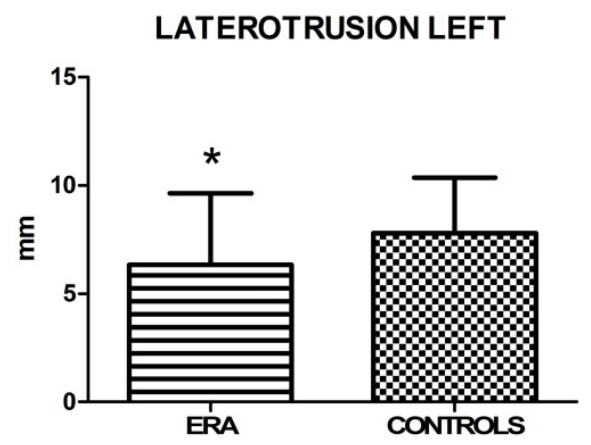

Figure 1. A, B. Mean values \pm SD of ERA and control group. Laterotrusion side evaluation reveals a statistically significant reduction of left lateral excursion.

5.4. Opening derangement (OD): the presence of alterations in the mouth opening pathway analyzed by $\chi^{2}$ test $(p=0,007)$ for deviation and by Mid-p exact test $(p=0,037)$ for deflection, resulted significantly reduced in ERA patients (Table 12).

Table 12. Opening derangement in ERA patients and controls.

\begin{tabular}{llcll}
\hline $\begin{array}{l}\text { Opening } \\
\text { Derangement }\end{array}$ & ERA & Controls & Test & p Value \\
\hline Deviation & $11(21,2 \%)$ & $24(46,2 \%)$ & $\chi^{2}=7,278$ & $0,007^{*}$ \\
Deflection & $3(5,8 \%)$ & $9(17,3 \%)$ & Mid-p exact test & $0,037^{*}$ \\
\hline
\end{tabular}

\section{Oral signs}

The presence of ulcers was significantly reduced in subjects with ERA, while the presence of erythematous and hyperkeratotic areas, candidiasis, angular cheilitis, erythema, fissured tongue and petechiae was substantially overlapping in the two groups. These data were analyzed using the $x^{2}$ test or Fisher's exact test (Table 13).
Table 13. Oral signs for ERA patients and controls.

\begin{tabular}{lllll}
\hline Oral signs & ERA & Controls & Test & p Value \\
\hline Oral ulcerations (aphthae) & $3(5,8 \%)$ & $10(19,2 \%)$ & $\chi^{2}=4,307$ & $0,038^{*}$ \\
$\begin{array}{l}\text { Erythema } \\
\text { Candidiasis }\end{array}$ & $0(0,00 \%)$ & $1(1,9 \%)$ & Fisher's exact test & 0,500 \\
Angular cheilitis & $0(0,00 \%)$ & $1(1,9 \%)$ & Fisher's exact test & 0,500 \\
& $4(7,7 \%)$ & $4(7,7 \%)$ & Fisher's exact test & 0,642 \\
$\begin{array}{l}\text { Hyperkeratotic or } \\
\text { erythematous areas of the } \\
\text { mucosa }\end{array}$ & $0(0,00 \%)$ & $2(3,8 \%)$ & Fisher's exact test & 0,247 \\
$\begin{array}{l}\text { Fissured tongue } \\
\text { Petechiae }\end{array}$ & $6(11,5 \%)$ & $6(11,5 \%)$ & Fisher's exact test & 0,619 \\
\hline & $0(0,0 \%)$ & $1(1,9 \%)$ & Fisher's exact test & 0,500 \\
\hline
\end{tabular}

A

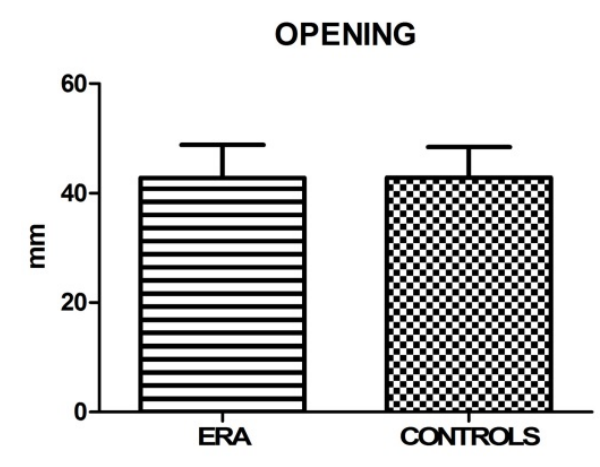

B

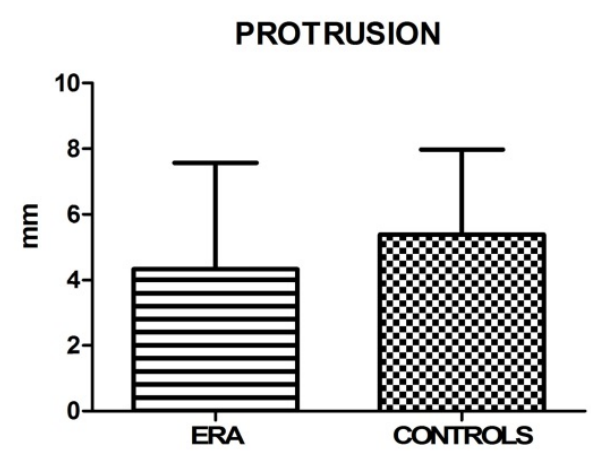

C

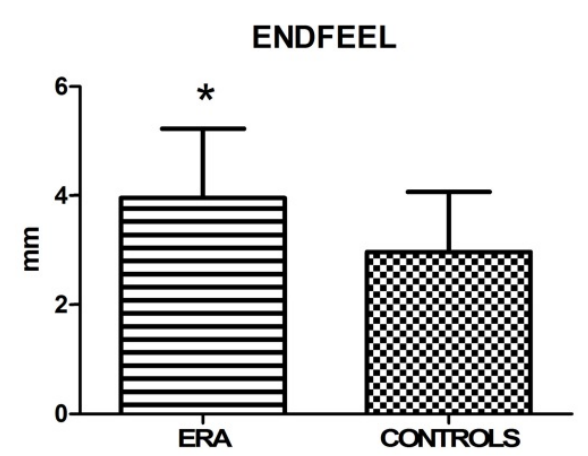

Figure 2. A, B, C. Mean values \pm SD of ERA and control group. Movement width evaluation shows no statistically significant differences, except for endfeel. 


\section{Salivary flow}

Regarding the extent of salivary flow (Fig. 3), measured in 5 minutes, there was a statistically significant reduction in the ill subjects compared to controls (Table 14).

\section{SALIVARY FLOW}

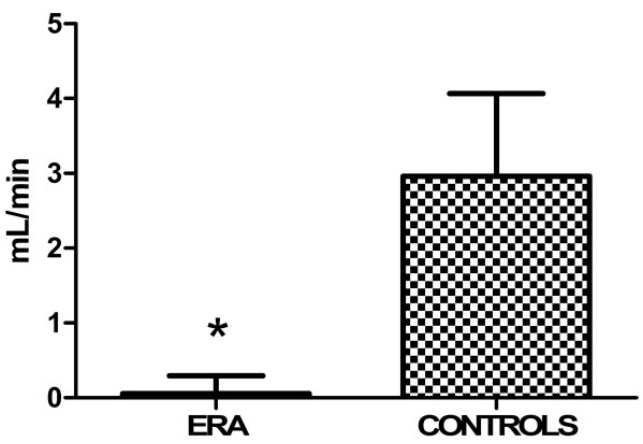

Figure 3. Mean values $\pm S D$ of ERA and control group. ERA patients show a reduced salivary flow.

Table 14. Mean values of salivary flow in ERA patients and controls.

\begin{tabular}{llll}
\hline $\begin{array}{l}\text { Mean values of salivary flow } \\
\text { (Mean in } \mathbf{~ l} \pm \text { SD) }\end{array}$ & ERA & Controls & p Value \\
\hline Salivary flow \pm SD & $0,058 \pm 0,235$ & $2,962 \pm 1,102$ & $<0,0001^{*}$ \\
\hline
\end{tabular}

\section{Discussion}

Rheumatoid Arthritis (RA) is an autoimmune polyarthritis characterized by the chronic inflammation of synovial joints of the hands, wrists, elbows, shoulders, hips, knees, feet and, less frequently, temporomandibular ones. It is a potentially fatal disease, involving several extra-articular organs, the damage of which is as minor as the diagnosis is earlier. RA related oral implications can be hyposalivation, difficulty in swallowing and phoning, feeling of burning mouth, increased thirst, loss of taste or unpleasant taste and smell, dental sensitivity.

Temporomandibular disorders (TMD) represent a heterogeneous group of inflammatory or degenerative diseases of the stomatognatic system, with algic and/or dysfunctional clinical features, involving temporomandibular joint (TMJ) and related masticatory muscles.

Previous studies in literature investigated the relationship between TMDs and RA [25, 48, 49, 50, 51], but none of them used a cohort of patients with an Early diagnosed RA. In addition, the present study focused not only the prevalence of TMD symptoms and signs, but highlighted also the oral implications in ERA patients compared with controls. Most of findings of this investigation did not reveal statistically significant differences between ERA patients with controls. Myofacial pain (MP) evoked by palpation was less frequent and severe than in the control group, while a weak TMJ kinematic impairment, a paucisymptomatic muscle contracture (positive endfeel) and a statistically significant reduction of salivary flow were more represented in the study group.

In detail, about education from primary school to the academic degree, ERA group had a similar prevalence of controls. Retirees and self-employed were much more represented in ERA patients (Table 1). Local and systemic conditions due to the syndrome, from the most common findings such as pain, joint stiffness, asthenia, weakness and fatigue, to the awareness of an increased risk of comorbidities and death, can worsen quality of life and psychological status of ERA patients, thus limiting their activities and their participation in society.

However, these psychological and physical impairments seem to be more attenuated in ERA patients if compared with ones affected by juvenile idiopathic arthritis (JIA). This kind of arthritis can lead to a severe impairment of patients' quality of life, with troubles in daily functions, such as dressing, grooming, walking, and writing. Emotional aspects, such as self non-acceptance, can damage JIA patients' social life. They showed also an oral health-related quality of life worse than $\mathrm{HC}$, with limitations in eating, smiling, performing oral hygiene [51].

Irrespective of these limitations, Mühlberg detected only a lower prevalence of periodontitis and no increase in the number of missing teeth in the RA group compared to the CG. These finding about the dental status corresponds with the results of the current study. The presence/absence of partial or total edentulism (Table 5) between ERA patients and CG shows no statistically significant difference $(p=0,169)[52]$.

Current or previous orthodontic treatments were present in a small percentage both in ERA sample and in CG, respectively $15.4 \%$ and $11.5 \%$. The application of orthodontic forces determines a biological response, resulting in a remodeling of the alveolar bone and the periodontal ligament, whose proprioceptors give information on movement and position of the stomatognathic system [53]. The early stage of orthodontic treatment consists of an acute inflammatory response, characterized by a loss of the normal tissue architecture, a change of collagen I, collagen IV and fibronectine. The amount of cytokines increases during tooth movement, with a release of inflammatory mediators, such as prostaglandin E (PGE). Consequently, undesired effects of the treatment can be root resorption and loss of alveolar 
bone. In ERA group, as well as in control group, orthodontic treatment gave no above mentioned side effect, probably thanks to a promptly started drug therapy [54].

The current study showed an increased prevalence of hypertension, thyroid, lung, kidney and esophageal diseases in ERA patients (Table 2), with findings similar to those reported by Chandrashekara et coworkers [55]. An interesting finding in patients' history is osteoporosis, affecting $17(32.7 \%)$ ERA patients versus $1(1.9 \%)$ of control group, due to a chronic bone inflammation and to a prolonged intake of corticosteroids (Table 4). Consequently, a higher rate of ERA patients takes bisphosphonates, a long-term antiresorptive therapy, which could cause, as a side effect, a medication-related osteonecrosis of the jaws (MRONJ) after oral surgery. Therefore, dentists should consider ERA patients as a potential risk category. About hypovitaminosis $\mathrm{D}$, the higher prevalence in ERA patients $(n=38,73.1 \%)$ versus control group $(n=1,1.9 \%)$ could be explained in a constant monitoring of this parameter in ERA patients. The lack of a routinary haematological analysis in the control group could lead in fact to underestimated data. All the patients started drug therapy within 12 months after diagnosis of ERA: $90.4 \%$ within 4 months, $3.8 \%$ between 4 and 8 months, $5.8 \%$ after 8 months. The drugs used for the treatment were: corticosteroids $(42.3 \%)$, sDMARDs $(78.8 \%)$ and bDMARDs (34.6\%). Many patients took combined therapies (Table 4).

About muscular and TMJ symptoms, they included neck and shoulders pain or soreness, pain during movement of masticatory muscles, arthralgia of TMJ, feeling of locked jaws during opening mouth, and tinnitus. All these were proved to be more recurring findings in the control group than in the study one (Table 7).

Painful symptoms related to muscle palpation were all much more present in the control group. In detail, statistically significant differences were detected in anterior and posterior temporalis muscles, sternocleidomastoid muscle-sternal head, digastric muscle (anterior and posterior bellies), medial and lateral pterygoid muscles, and mylohyoid muscle (Table 8). However, positive end-feel values (Table 11) showed objectively a higher presence of a paucisymptomatic muscle contracture in patients with ERA compared with the control ones $(p=0,002)$.

These phenomena are probably linked to drug therapy: corticosteroids cause the down-regulation of proinflammatory chemokines, adhesion molecules and cytokines such as tumor necrosis factor (TNF), interleukin-1(IL-1), IL-6, intercellular cell adhesion molecules (ICAM-1) and vascular cell adhesion molecule (VCAM-1). They also function as selective inhibitors of cyclooxygenase 2 (COX-2) by increasing the synthesis of lipocortin-1, a 37-kDa protein that has an inhibitory effect on phospholipase A2 (PLA2), therefore down regulates the production of arachidonic acid metabolites including prostaglandins and leukotrienes [56], which are responsible for inflammation and damage both to the joints and to other sites in the body.

Also conventional DMARDs and biological drugs act at the level of the immune system [57], impairing the binding of pro-inflammatory cytokines to their receptors, that play an important role in the pathogenesis of RA [58], thus leading to a rapid improvement in joint pain and swelling.

It is clear, therefore, that if patients affected by ERA take these drugs stably, pain and inflammation will be inhibited not only in the joints, but also in other parts of the body, including for example muscle tissue. In the present work, the study sample consisted of subjects with Early Rheumatoid Arthritis, i.e. patients who had received an early diagnosis of disease within 12 months from the onset of symptoms, and therefore had promptly started a correct drug therapy. Moreover, they had, on average, a low disease activity or clinical remission at the time of observation (Table 3). Therefore, minimal damages in joints and muscles (as well as in other districts) were expected. Muscular pain, in fact, was less present in ERA patients than in controls, even if the first ones had a major muscular contracture. Also joint damages and joint signs were less present in ERA patients than in controls: at the clinical examination, they showed a statistically significant reduction of the presence of TMJ noises $(p=0,049)$, which generally indicate morphological alterations of the bony heads or joint damage (Table 9).

Muscular contracture, as well as the positive end-feel, was also objectified by a limitation in the mandibular kinematics, which, although only in the left laterality showed a statistically significant reduction compared to the control group $(p=0,017)$, was evidenced also in the movements of right laterality and protrusion (Table 11).

The use of these pharmacological therapies could also explain the statistically significant reduction in patients with ERA compared to controls, of changes in the mouth opening pathway: deviation $(p=0,007)$ and deflection $(p=0,037)$. Often, in fact, they are related to the presence of morphological alterations in the condyle, such as osteophytes or bone beaks, which in these patients are slowed down, if not blocked, by the aforementioned precocious therapies (Table 12). 
With regard to the statistical significance of the reduction of dental clenching in patients with ERA compared to controls $(p<0,001)$, it can be explained by a condition of muscle weakness that develops frequently in this pathology, traditionally thought to be caused by a loss of muscle mass and an impaired intrinsic contractility also present in patients with RA [59], but also linked to nitrosative modifications of the RyR1 protein complex and actin, which are driven by increased nNOS associated with RyR1 and progressively increasing $\mathrm{Ca}^{2+}$ activation [60].

As a result, even dental wear facets were significantly less present in cases than in controls $(p=0,006)$ (Table 10).

Taking into account oral signs, only the presence of oral ulcerations (aphthae) was significantly reduced in subjects with ERA compared to controls $(p=0,038)$ (Table 13).

About oral symptoms, statistically significant differences were not found between the study group and the control one $(p>0,05)$ (Table 6). Also xerostomia was overlapping in the two groups, although ERA patients presented a considerably reduced salivary flow compared to the controls $(p<0,0001)$ (Table 14). This result is probably due to the drug therapies, which included many xerogenic medications. This outcome is in agreement with Torres' results [61], who showed that subjects with RA presented reduced resting salivary flow when compared to healthy controls.

\section{Conclusion}

The aim of this observational study was to investigate the prevalence of TMD symptoms and signs as well as oral implications in patients with ERA, that is a RA diagnosed within 12 months, compared with people not affected by this disease. Myofacial pain (MP) evoked by palpation was more frequent and severe in the control group than in the study one, this result being highly significant.

The data collected show also a weak TMJ kinematic impairment, a paucisymptomatic muscle contracture (positive endfeel) and a statistically significant reduction of salivary flow in ERA patients when compared to the control group.

Therefore, an interdisciplinary collaboration between the stomatologist and the rheumatologist is desirable, for a more complete clinical overview and for a more efficient treatment of this disease.

\section{Abbreviations}

RA: Rheumatoid Arthritis; ERA: Early Rheumatoid Arthritis; sDMARDs: synthetic disease-modifying antirheumatic drugs; bDMARDs: biological DMARDs; ACR: American College of
Rheumatology; EULAR: European League Against Rheumatism; DAS28: Disease activity score 28, CDAI: Clinical Disease Activity Index, SDAI: Simplified Disease Activity Index; TMD: temporomandibular disorders; TMJ: temporomandibular joint; RDC/TMD: research diagnostic criteria for temporomandibular disorders; TMDs: symptoms of temporomandibular disorders; OD: opening derangement; BRUX: bruxism; TMJs: sounds of temporomandibular joint; MP: myofascial pain; RM: restricted movements; VAS: visual analogic scale.

\section{Authors' Contribution}

Piancino.

Study Design: Vito Crincoli, Maria Grazia

Data Collection: Eleonora Quercia, Maria Grazia Anelli.

Statistical Analysis: Mariasevera Di Comite.

Data Interpretation: Vito Crincoli, Mariasevera

Di Comite.

Manuscript Preparation: Vito Crincoli.

Literature Search: Vito Crincoli, Eleonora Quercia.

\section{Competing Interests}

The authors have declared that no competing interest exists.

\section{References}

1. Scott DL, Wolfe F, Huizinga TW. Rheumatoid arthritis. Lancet. 2010; 25: 1094-108.

2. Gibofsky A. Epidemiology, pathophysiology, and diagnosis of rheumatoid arthritis: A Synopsis. Am J Manag Care. 2014; 20(7 Suppl): S128-135.

3. Rodríguez-Elías AK, Maldonado-Murrillo K, López-Mendoza LF, Ramírez-Bello J. Genetics and genomics in rheumatoid arthritis (RA): An update. Gac. Med Mex. 2016; 152(2): 218-227.

4. Alamanos Y, Voulgari PV, Drosos AA. Incidence and prevalence of rheumatoid arthritis, based on the 1987 American College of Rheumatology criteria: a systematic review. Semin. Arthritis Rheum. 2006; 36(3): 182-8.

5. Arend WP, Firestein GS. Pre-rheumatoid arthritis: predisposition and transition to clinical synovitis. Nat Rev Rheumatol. 2012; 8(10): 573-586.

6. MacGregor AJ, Snieder H, Rigby AS, Koskenvuo M, Kaprio J, Aho K, Silman AJ. Characterizing the quantitative genetic contribution to rheumatoid arthritis using data from twins. Arthritis Rheum. 2000; 43(1): 30-7.

7. McMichael AJ, Sasazuki T, McDevitt HO, Payne RO. Increased frequency of HLA-Cw3 and HLA-Dw4 in rheumatoid arthritis. Arthritis Rheum. 1977; 20(5): 1037-1042

8. Yamamoto K, Okada Y, Suzuki A, Kochi Y. Genetic studies of rheumatoid arthritis. Proc Jpn Acad Ser B, Phys Biol Sci. 2015; 91(8): 410-422.

9. Fisher SA, Lanchbury JS, Lewis CM. Meta-analysis of four rheumatoid arthritis genome-wide linkage studies: confirmation of a susceptibility locus on chromosome 16. Arthritis Rheum. 2003; 48: 1200-6.

10. Okada Y, Wu D, Trynka G, et al. Genetics of rheumatoid arthritis contributes to biology and drug discovery. Nature. 2014; 506(7488): 376-81.

11. Karlson EW, Deane K. Environmental and gene-environment interactions and risk of rheumatoid arthritis. Rheum Dis Clin North Am. 2012; 38(2): 405-26.

12. Colebatch AN, Edwards CJ. The influence of early life factors on the risk of developing rheumatoid arthritis. Clin Exp Immunol. 2011; 163(1): 11-6.

13. Angelotti F, Parma A, Cafaro G, Capecchi R, Alunno A, Puxeddu I. One year in review 2017: pathogenesis of rheumatoid arthritis. Clin Exp Rheumatol. 2017; 35(3):368-78.

14. Bustamante MF, Garcia-Carbonell R, Whisenant KD, Guma M. Fibroblast-like synoviocyte metabolism in the pathogenesis of rheumatoid arthritis. Arthritis Res Ther. 2017; 19(1):110, 12 pages.

15. Schett G, Gravallese E. Bone erosion in rheumatoid arthritis: mechanisms, diagnosis and treatment. Nat Rev Rheumatol. 2012; 8(11): 656-64.

16. Feehan L, Buie H, Li L, McKay H. A customized protocol to assess bone quality in the metacarpal head, metacarpal shaft and distal radius: a high 
resolution peripheral quantitative computed tomography precision study. BMC Musculoskelet Disord. 2013; 14: 367, 12 pages.

17. Zhao J, Su Y, Li R, Ye H, Zou Q, Fang Y, Liu H, Li X, Guo J, Bi L, Gu F, Sun L, Mei Y, Zhang Z, Chen L, Zhu P, Li G, Zhang Z, Leng X, Zhao Y, Jiang L, Zou H, Zhao Y, Liu Y, Li L, Wang H, Liu X, Li Z. Classification criteria of early rheumatoid arthritis and validation of its performance in a multi-centre cohort. Clin Exp Rheumatol. 2014; 32(5): 667-73.

18. Sodhi A, Naik S, Pai A, Anuradha A. Rheumatoid arthritis affecting temporomandibular joint. Contemp Clin Dent. 2015; 6(1): 124-127.

19. Scutellari PN, Orzincolo C. Rheumatoid arthritis: Sequences. Eur J Radiol. 1998; 27(Suppl 1): S31-8.

20. Delantoni A, Spyropoulou E, Chatzigiannis J, Papademitriou P. Sole radiographic expression of rheumatoid arthritis in the temporomandibular joints: A case report. Oral Surg Oral Med Oral Pathol Oral Radiol Endod. 2006; 102(4): e37-40

21. Goupille P, Fouquet B, Cotty P, Goga D, Valat JP. Direct coronal computed tomography of the temporomandibular joint in patients with rheumatoid arthritis. Br J Radiol. 1992; 65: 955-60.

22. Helenius LM, Hallikainen D, Helenius I, Meurman JH, Könönen M, Leirisalo-Repo M, Lindqvist C. Clinical and radiographic findings of the temporomandibular joint in patients with various rheumatic diseases. A case-control study. Oral Surg Oral Med Oral Pathol Oral Radiol Endod. 2005; 99: 455-63.

23. Ahola K, Saarinen A, Kuuliala A, Leirisalo-Repo M, Murtomaa H, Meurman $\mathrm{JH}$. Impact of rheumatic diseases on oral health and quality of life. Oral Dis. 2015; 21: 342-348.

24. Chamani G, Shakibi MR, Zarei MR, Rad M, Pouyafard A, Parhizkar A, Mansoori M. Assessment of relationship between xerostomia and oral health-related quality of life in patients with rheumatoid arthritis. Oral Dis. 2017; 23: 1162-67.

25. Kurtoglu C, Kurkcu M, Sertdemir Y, Ozbek S, Gürbüz C C. Temporomandibular disorders in patients with rheumatoid arthritis: A clinical study. Niger J Clin Pract. 2016; 19: 715-20.

26. Dworkin SF, LeResche L. Research diagnostic criteria for temporomandibular disorders: Review criteria, examinations and specifications, critique. J Craniomandib Disord. 1992; 6: 301-355.

27. Wiener RC, Wu B, Crout R, Wiener M, Plassman B, Kao E, McNeil D: Hyposalivation and xerostomia in dentate older adults. J Am Dent Assoc. 2010; 141: 279-284

28. Tanasiewicz M, Hildebrandt T, Obersztyn I. Xerostomia of Various Etiologies: A Review of the Literature. Adv Clin Exp Med. 2016; 25(1): 199-206.

29. Markley EJ, Mattes-Kuling DA, Henkin RI. A classification of dysgeusia. J Am Diet Assoc. 1983; 83: 578-580.

30. Nakazato Y, Ito Y, Naito S, Tamura N, Shimazu K. Dysgeusia limited to sweet taste in myasthenia gravis. Intern Med. 2008; 47(9): 877-8.

31. Mott AE, Grushka M, Sessle BJ. Diagnosis and management of taste disorders and burning mouth syndrome. Dent Clin North Am. 1993; 37(1): 33-71.

32. Aravindhan R, Vidyalakshmi S, Kumar MS, Satheesh C, Balasubramanium AM, Prasad VS. Burning mouth syndrome: A review on its diagnostic and therapeutic approach. J Pharm \& Bioallied Sci. 2014; 6(Suppl 1): S21-S25.

33. Gil-Martínez A, Grande-Alonso M, López-de-Uralde-Villanueva I. LòpezLòpez A, Fernàndez- Carnero J, La Touche R. Chronic Temporomandibular Disorders: disability, pain intensity and fear of movement. J Headache Pain. 2016; 17(1):103, 9 pages.

34. Hara K, Shinozaki T, Okada-Ogawa A, Matsukawa Y, Dezawa K, Nakaya Y, Chen JY, Noma N, Oka S, Iwata K, Imamura Y. Headache attributed to temporomandibular disorders and masticatory myofascial pain. J Oral Sci. 2016; 58(2): 195-204.

35. Lee CF, Lin MC, Lin HT, Lin CL, Wang TC, Kao CH. Increased risk of tinnitus in patients with temporomandibular disorder: a retrospective population-based cohort study. Eur Arch Otorhinolaryngol. 2016; 273(1): 203-8.

36. Löfgren CD, Wickström C, Sonesson M, Lagunas PT, Christersson C. A systematic review of methods to diagnose oral dryness and salivary gland function. BMC Oral Health. 2012; 12. 29.

37. López-Pintor RM, Casañas E, González-Serrano J, Serrano J, Ramírez L, de Arriba L, Hernández G. Xerostomia, Hyposalivation, and Salivary Flow in Diabetes Patients. J Diabetes Res. 2016: Article ID 4372852, 15 pages.

38. Widmalm SE; Williams WJ; Adams BS. The wave forms of temporomandibular joint sound clicking and crepitation. J Oral Rehabil. 1996; 23(1): 44-49.

39. Tecco S, Crincoli V, Di Bisceglie B, Saccucci M, Macrì M, Polimeni A, Festa F. Signs and symptoms of temporomandibular joint disorders in Caucasian children and adolescents. Cranio. 2011; 29(1): 71-79.

40. International Classification of Sleep Disorders. 3rd ed. Westchester, Darien, Illinois: American Academy of Sleep Medicine; 2014. American Academy of Sleep Medicine. Sleep related bruxism.

41. Čalić A, Peterlin B. Epigenetics and Bruxism: Possible Role of Epigenetics in the Etiology of Bruxism. Int J Prosthodont. 2015; 28(6):594-9.

42. Kato T, Dal-Fabbro C, Lavigne GJ. Current knowledge on awake and sleep bruxism: Overview. Alpha Omegan. 2003; 96: 24-32.

43. Louca Jounger S, Christidis N, Svensson P, List T, Ernberg M. Increased levels of intramuscular cytokines in patients with jaw muscle pain. J Headache Pain. 2017; 18(1): 30,9 pages.
44. Agerberg G. Maximal mandibular movements in young men and women. Sven Tandlak Tidskr.1974; 67:81-100.

45. Solberg W. Clinical Dentistry. Occlusion-related pathosis and its clinical evaluation; pp. 1-29. New York, NY, USA: Harper \& Row Publishers; 1976

46. Sener S, Akgunlu F. Correlation between the Condyle Position and Intra-Extraarticular Clinical Findings of Temporomandibular Dysfunction. Eur J Dent. 2011; 5(3): 354-360.

47. Huskisson EC. Measurement of pain. Lancet. 1974; 2: 1127-1131.

48. Lin YC, Hsu ML, Yang JS, Liang TH, Chou SL, Lin HY. Temporomandibular joint disorders in patients with rheumatoid arthritis. J Chin Med Assoc. 2007; 70(12):527-34.

49. Witulski S, Vogl TJ, Rehart S, Ottl P. Evaluation of the TMJ by means of Clinical TMD Examination and MRI Diagnostics in Patients with Rheumatoid Arthritis. BioMed Res Int. 2014; Article ID: 328560, 9 pages.

50. Cordeiro PC, Guimaraes JP, de Souza VA, Dias IM, Silva JN, Devito KL, Bonato LL. Temporomandibular joint involvement in rheumatoid arthritis patients: association between clinical and tomographic data. Acta Odontol Latinoam. 2016;29(3):123-129.

51. Isola G, Perillo L, Migliorati M, Matarese M, Dalessandri D, Grassia V, Alibrandi A, Matarese G. The impact of temporomandibular joint arthritis on functional disability and global health in patients with juvenile idiopathic arthritis. Eur J Orthod. 2018; 6: 1-8.

52. Mühlberg S, Jäger J, Krohn-Grimberghe B, Patschan S, Mausberg RF, Schmalz G, Haak R, Ziebolz D. Oral health-related quality of life depending on oral health in patients with rheumatoid arthritis. Clin Oral Investig. 2017; 21(9):2661-2670.

53. Piancino MG, Isola G, Cannavale R, Cutroneo G, Vermiglio G, Bracco P, Anastasi GP. From periodontal mechanoreceptors to chewing motor control: A systematic review. Arch Oral Biol. 2017; 78:109-121.

54. Isola G, Matarese G, Cordasco G, Perillo L, Ramaglia L. Mechanobiology of the tooth movement during the orthodontic treatment: a literature review. Minerva Stomatol. 2016; 65(5):299-327.

55. Chandrashekara S, Shobha V, Dharmanand BG, Jois R, Kumar S, Mahendranath KM, Haridas V, Prasad S, Singh Y, Daware MA, Swamy A, Subramanian R, Somashekar SA, Shanthappa AM, Anupama KR. Comorbidities and related factors in rheumatoid arthritis patients of south India Karnataka Rheumatoid Arthritis Comorbidity (KRAC) study. Reumatismo. 2017; 3; 69(2):47-58.

56. Barnes PJ, Adcock I. Anti-inflammatory actions of steroids: molecular mechanisms. Trends Pharmacol Sci. 1993; 14(12):436-41.

57. Quan L, Thiele GM, Tian J, Wang D. The Development of Novel Therapies for Rheumatoid Arthritis. Expert Opin Ther Pat. 2008; 18(7):723-738.

58. Choy EH, Panayi GS. Cytokine pathways and joint inflammation in rheumatoid arthritis. N Engl J Med. 2001; 22; 344(12):907-16.

59. Helliwell PS, Jackson S. Relationship between weakness and muscle wasting in rheumatoid arthritis. Ann Rheum Dis 1994; 53:726-28.

60. Yamada T, Fedotovskaya O, Cheng AJ, Cornachione AS, Minozzo FC, Aulin C, Fridén C, Turesson C, Andersson DC, Glenmark B, Lundberg IE, Rassier DE, Westerblad H, Lanner JT. Nitrosative modifications of the Ca2+ release complex and actin underlie arthritis-induced muscle weakness. Ann Rheum Dis. 2015; 74(10): 1907-1914.

61. Torres SR, Pedrazas CH, Correia MP, Azevedo MN, Zamprogno T, Silva A Junior, Gonçalves LS, Papi JA. Drugs or disease: evaluating salivary function in RA patients. Braz Oral Res. 2016; 30(1):e106. 